\title{
When extra authors get in on the act
}

Sir - You report that more than two-thirds of Europe's young scientists say they are not given full credit for their research achievements ${ }^{1}$. There are similar concerns in the United States. A survey of 191 US postdoctoral physicists finds that senior scientists are frequently listed as authors of papers even though they have had little or no participation in the work ${ }^{2}$. How does this come about?

The results indicate that there is no standard process for the distribution of authorship among co-workers. The American Physical Society's ethical guidance says: "Authorship should be limited to those who have made a significant contribution to the concept, design, execution and interpretation of the research study." Some 76 per cent of the survey's respondents had not seen the ethical statement. When shown it, half of the postdocs said that, according to their interpretation of the statement, obtaining grants and funding would be a qualification for authorship. (The statement does not specify that authorship contributions should be intellectual, nor original.)

Seventy-five per cent of postdocs had never discussed authorship criteria with their supervisors, and 70 per cent said the criteria for designating others as authors were not "clearly agreed upon".

Postdocs perceive there to be a substantial amount of inappropriate authorship. Supervisors were authors on 92 per cent of postdoc papers. Guided by the ethical statement, the postdocs responded that in 14 per cent of those papers the supervisor should not have been listed as an author. In 33 per cent of papers with authors in addition to the supervisor or postdoc, one or more of those authors should not have been listed. Respondents reported that in one per cent of papers they were themselves inappropriate authors.

The reasons reported for inappropriate authorship fell into four groups:

(1) Concern about the relationship between postdoc and supervisor. Postdocs need letters of recommendation from supervisors and want to keep in their good graces. Relationships with other scientists in the field are perceived to be enhanced by giving them authorship. Sometimes the authors hope to gain prestige or expedite publication by adding a well-known name.
(2) Minor contributions to the work, more appropriate for acknowledgement than authorship.

(3) Previous work in the field, or expected contributions that did not materialize.

(4) Crediting staff who are socially close, for example part of the same research group.

The scientific community should adopt formal procedures for assigning authorship appropriately and penalizing 'honorary' authorship. This would avoid the problem that it can be difficult to discuss credit within a research group. Authorship of papers could be modelled on US patent procedures in which an independent party inquires into the work and assigns authorship. Or a section could be added at the end of each paper to explain what each author contributed.

The impetus to introduce these changes lies with junior scientists, the most likely victims of having their intellectual property 'diluted' by inappropriate authorship.

Eugen Tarnow

Avabiz.com, 3725 Blackstone Avenue, Ste. 4E, Riverdale, New York 10463-1444, USA

1. Schiermeier, Q. Nature 397, 640-641 (1999).

2. Tarnow, E. Science and Engineering Ethics 5, 73-88 (1999).

\section{Miscalculation}

Sir - Your headline "Germany enters the supercomputer age" is some 20 years out of date (Nature 397, 643; 1999). It is even more ironic as the Rechenzentrum Garching of the Max Planck Society was the first centre in the world to offer civilian scientists open access to supercomputers, inspiring Larry Smarr and his colleagues to found the US national supercomputer centres.

Mordecai-Mark Mac Low

Max Planck Institute for Astronomy,

Koenigstuhl 17, D-69117 Heidelberg, Germany

\section{Hand over your clones or lose your reputation}

Sir- Noel Harris is right to protest the refusal of many researchers to respond to requests for clones, especially having signed away their right not to do so by publishing in journals such as Nature (Nature 398, 102; 1999). But, rather than 'outing' such workers, it is much more effective simply to clone the gene yourself and then do better work, faster, than those who tried to slow you down (driven by the incentive of revenge?!).

Given the speed with which known sequences can now be isolated, refusal to part with clones is just plain silly — the cost in terms of ill-feeling, with or without 'outing', far outweighs the few weeks' benefit gained over competitors. The 'refusers' are already losing out.

Mark Tester

Plant Sciences Department, University of Cambridge, Downing Street, Cambridge CB2 3EA, UK

\section{Did Parisians catchHIV from 'monkey glands'?}

Sir - It was good to read Gao et al.'s report ${ }^{1}$ which now leaves little doubt that chimpanzees (Pan troglodytes troglodytes) from central Africa are the origin of the human HIV-1 pandemic. Two additional points seem worthy of comment.

Chimpanzees live in multi-male communities with a promiscuous mating system, quite unlike humans or the other great apes. This makes them particularly susceptible to the spread of sexually transmitted infections, so they might have evolved some novel defence mechanisms which have allowed them to come to terms with HIV-1. If only we knew how.

One of the consequences of the chimpanzees' promiscuous mating system is that they have developed extremely large testes in response to gamete selection ${ }^{2}$.
Unfortunately, this made chimpanzees attractive subjects for Serge Voronoff, director of experimental surgery at the Collège de France in Paris. In the 1920s, Voronoff was the leading exponent of testicular transplantation for the rejuvenation of ageing men ${ }^{3,4}$. Lacking an adequate supply of fresh human testes courtesy of the guillotine, he resorted to chimpanzee testes, which had the added advantage that each was so large that it could provide scrotal transplants for a number of men. Since his chimpanzee donors could well have come from Francophone central Africa, it is quite possible that some of his elderly male patients, and maybe even their partners, might have acquired an HIV-1 infection and developed AIDS.

Perhaps it is just as well that they were suffering from impotence and could not have been cured by the treatment.

Nevertheless, their case histories would now make fascinating reading with the wisdom of hindsight.

\section{R. V.Short}

Department of Perinatal Medicine,

Royal Women's Hospital, University of Melbourne,

Melbourne 3053, Australia

1. Gao, F. et al. Nature 397, 436-441 (1999).

2. Short, R.V. Acta Paediatr. Suppl. 422, 3-7 (1997).

3. Gosden, R. Cheating Time: Science, Sex and Ageing (Macmillan, London, 1996).

4. Voronoff, S. Scientific American, October, 226-227 (1925). 